\title{
Efektivitas Audio-Visual Dangers of Smoking dalam Meningkatkan Pengetahuan, Efikasi Diri dan Sikap Remaja di SMP Negeri 32 Kota Samarinda
}

\section{The Effectiveness of Dangers of Smoking Audio-Visual in Improving Teenagers Knowledge, Self-Efficacy and Attitude in SMP Negeri 32 Samarinda City}

\author{
Alma Feriyanti ${ }^{*}$, Ismail $\mathrm{AB}^{1}$, Riza Hayati Ifroh ${ }^{1}$
}

${ }^{1}$ Peminatan Promosi Kesehatan Fakultas Kesehatan Masyarakat Universitas Mulawarman

*Korespondensi penulis:

almaferianti@gmail.com

$\begin{array}{ll}\text { Diterima (Recieved) } & : 2 \text { September } 2020 \\ \text { Direvisi (Revised) } & : 28 \text { November } 2020 \\ \text { Diterima untuk diterbitkan (Accepted) } & : 24 \text { Desember } 2020\end{array}$

ABSTRAK

Latar Belakang. Berdasarkan Riskesdas (2018), prevalensi perokok usia $\geq 10$ tahun di Indonesia yaitu sebesar $28,8 \%$ dan usia perokok 10-18 tahun mengalami peningkatan dari 7,2\% menjadi $9,1 \%$.

Tujuan. Penelitian ini bertujuan untuk menganalisis efektivitas video ceramah dengan alat peraga Dangers of Smoking dalam meningkatkan pengetahuan, efikasi diri dan sikap bahaya merokok.

Metode. Penelitian ini menggunakan pra-eksperimental dengan desain one group pre-test-post-test. Teknik sampling yang digunakan purposive sampling. Uji statistik pada variabel pengetahuan menggunakan Wilcoxon Signed Rank dan variabel efikasi diri dan sikap menggunakan paired t-test.

Hasil. Pengetahuan menunjukkan bahwa nilai p-value $(0,000)<0,05$ terdapat perbedaan pengetahuan sebelum dan sesudah dilakukan intervensi video ceramah bahaya merokok, efikasi diri dan sikap menunjukkan nilai $p$ value $(0,023)$ dan $(0,019)<0,05$ terdapat perbedaan efikasi diri dan sikap sebelum dan sesudah dilakukan intervensi video ceramah bahaya merokok.

Kesimpulan. Terdapat pengaruh metode video ceramah terhadap peningkatan pengetahuan, efikasi diri dan sikap bahaya merokok pada siswa.

Kata Kunci: audio-visual, merokok, pengetahuan, efikasi diri, sikap

\section{ABSTRACT}

Background. Indonesian Basic Health Research (2018) shown that the prevalence smoker aged $\geq 10$ years old it was $28.8 \%$ and smoker between 10-18 years old increased from $7.2 \%$ to $9.1 \%$.

Objective. The objective of this study is to analyze the effectiveness of lecture videos with teaching aids the dangers of smoking to increase knowledge, self-efficacy and negative attitude towards smoking to adolescent. Method. This study used pre-experimental research with one group pre-test-post-test design. Statistical result of knowledge by Wilcoxon signed-rank test and Statistical result of self-efficacy and attitude by paired t-test. Result. Knowledge variables shown that p-value $(0.000)<0.05$. There was a difference in the result of adolescent knowledge before and after intervention lecture videos on the dangers of smoking. Self-efficacy and attitude variable showed that p-value $(0,023)$ and $(0,019)<0,05$. There was a difference between the result of adolescent self-efficacy and attitude before and after intervention lecture videos the dangers of smoking.

Conclusion. Lecture videos with teaching aid "dangers of smoking" are effective in improving student knowledge, self-efficacy, and attitude towards the dangers of smoking.

Keywords: audio-visual, smoking, knowledge, self-efficacy, attitude

\section{LATAR BELAKANG}

Indonesia menjadi urutan ketiga jumlah perokok tertinggi di dunia. Prevalensi perokok Indonesia berdasarkan jenis kelamin laki-laki usia $\geq 15$ tahun sebesar $66,6 \%$ dan perokok perempuan sebesar 2,1\%. ${ }^{1}$ Berdasarkan hasil
Riskesdas tahun 2018, prevalensi perokok $\geq 10$ tahun di Indonesia secara nasional sebesar $28,8 \%$. Perokok pada usia $10-18$ tahun mengalami peningkatan dari $7,2 \%$ menjadi $9,1 \%$. Remaja yang lebih awal merokok akan lebih berisiko ketergantungan dengan zat nikotin. ${ }^{2}$ 
Perilaku merokok pada remaja dipengaruhi oleh pengetahuan kurang tentang bahaya merokok dan memiliki sikap kurang baik terhadap bahaya merokok. ${ }^{3}$ Berdasarkan penelitian yang dilakukan pada seluruh siswa di empat SMPN di Kecamatan Sampang Madura, dari 1.789 siswa, $70.7 \%$-nya memiliki pengetahuan yang rendah terhadap bahaya merokok dan berbagai bahan kimia yang terkandung dalam rokok yang masih belum dipahami. ${ }^{2}$ Pengetahuan akan membentuk efikasi diri (keyakinan diri) terhadap perilaku merokok. Apabila seorang remaja memiliki efikasi diri yang tinggi maka akan menolak untuk merokok sedangkan remaja yang memiliki efikasi diri rendah maka akan lebih tertarik untuk merokok. ${ }^{4}$

Remaja merokok diawali dengan rasa ingin tahu yang sangat besar sehingga mereka mencoba merokok dan akhirnya menjadi perokok aktif. ${ }^{5}$ Remaja perokok aktif dapat menimbulkan dampak negatif yang berpengaruh terhadap penurunan prestasi belajar di sekolah. Hal ini dikarenakan merokok dapat menurunkan kosentrasi belajar dan kebugaran tubuh. serta mengganggu kesehatan. ${ }^{6}$ Bahaya merokok pada usia remaja akan meningkatkan resiko penyakit tidak menular pada usia muda dan mengurangi jumlah sperma dan kesuburan wanita. $^{2}$ Perlu adanya upaya pencegahan perilaku merokok pada usia remaja.

Salah satu metode pendidikan kesehatan yang dapat dilakukan yaitu metode ceramah. Metode ceramah dapat disajikan dalam bentuk video yang lebih menarik dan dapat disebarluaskan melalui media sosial. Hal tersebut dikarenakan media video mampu meningkatkan pengetahuan dengan cara menstimulasi panca indera pendengaran dan pengelihatan yang ditangkap seseorang. ${ }^{7}$ Metode video ceramah ini dapat menggunakan alat peraga sebagai media pembelajarannya. Hal ini betujuan agar siswa lebih mudah memahami materi yang disampaikan melalui alat peraga.

Alat peraga tentang bahaya merokok menggambarkan proses merokok yang dapat merusak organ dalam tubuh, sehingga menimbulkan efikasi diri untuk tidak merokok. Pesan persuasif dengan efikasi tinggi dan ancaman tinggi akan menyebabkan tingkat ketakutan yang tinggi dan dapat menyakinkan subjek penelitian ancaman bahaya merokok bisa dihindari. ${ }^{8}$ Efikasi diri dapat menimbulkan kontrol bahaya terhadap bahaya merokok. Pada kontrol bahaya ini terdapat proses kognitif atau pengetahuan dan mengarah pada perubahan sikap seseorang remaja. ${ }^{9}$

Berdasarkan Riset Kesehatan Dasar (Riskesdas) tahun 2018, prevalensi merokok usia remaja di Provinsi Kalimantan Timur sebesar $21,9 \% .{ }^{10}$ Salah satu kota yang masih tinggi kasus perokok pada usia remaja yaitu di Kota Samarinda ${ }^{11}$. Berdasarkan laporan PKPR (Pelayanan Kesehatan Peduli Remaja) Dinas Kesehatan Kota Samarinda pada tahun 2018, kasus merokok pada usia 15-19 tahun di Kota Samarinda sebesar 360 orang. Wilayah tertinggi kasus merokok usia remaja di Kota Samarinda yaitu berada di wilayah kerja Puskesmas Makroman. ${ }^{11}$ Kasus merokok pada usia remaja di wilayah kerja Puskesmas Makroman yaitu usia 13-14 tahun sebesar 32 orang dan usia 15-19 tahun 167 orang. ${ }^{11}$

Upaya pencegahan yang dilakukan oleh pihak puskesmas adalah memberikan edukasi kesehatan remaja di sekolah seperti NAPZA (Narkotika, Psikotorpika dan Zat Aditif lainnya). Berdasarkan hasil wawancara dengan petugas PKPR (Pelayanan Kesehatan Peduli Remaja) Puskesmas Makroman, salah satu sekolah menengah pertama yang memiliki perilaku merokok pada usia remaja yaitu pada siswa SMP Negeri 32 Kota Samarinda.

Berdasarkan studi pendahuluan yang mewawancarai Kepala Sekolah dan pembimbing konseling di SMP Negeri 32 Kota Samarinda diketahui terdapat beberapa siswa yang merokok di WC sekolah saat jam istirahat dan setelah selesai aktivitas belajar di sekolah. Adapun faktor resiko yang mempengaruhi siswa merokok yakni salah satu anggota keluarga merupakan perokok aktif dan lingkungan masyarakat tempat tinggal siswa merupakan perokok aktif. Rendahnya sikap siswa terhadap bahaya merokok membuat siswa mudah terpengaruh oleh lingkungannya.

Diperlukan riset untuk mengetahui efektivitas video ceramah dengan alat peraga Dangers of Smoking dalam meningkatkan pengetahuan, efikasi diri dan sikap bahaya merokok pada siswa Kelas VII SMP Negeri 32 Kota Samarinda. 


\section{METODE}

Penelitian ini dirancang menggunakan desain pra-eksperimental dengan rancangan one group pre-test and post-test design. Populasi pada penelitan ini sebanyak 115 siswa kelas VII SMP Negeri 32 Kota Samarinda. Sampel pada penelitian ini berjumlah 35 orang. Teknik sampling yang digunakan yaitu purposive sampling dengan kriteria inklusi yaitu siswa direkomendasikan oleh wali kelas VII, siswa berada di grup WhatsApp kelas, dan bersedia mengikuti kegiatan penelitian. Kriteria eksklusi yaitu siswa yang tidak berada di grup WhatsApp kelas dan tidak bersedia mengikuti kegiatan penelitian. Angket yang digunakan telah dilakukan uji validitas dan reliabilitas secara online pada 30 siswa kelas VII di SMP 23 Kota Samarinda. Pengumpulan data pre-test dan post-test dilakukan secara online melalui link yang dibagikan di dalam grup WhatsApp kelas sebagai berikut bit.ly/pretest_rokok dan bit.ly/postest_rokok dengan rentang waktu antara pre-test dan post-test selama 2 hari.

Penelitian ini menggunakan satu kelompok intervensi. Uji statistik yang digunakan pada variabel pengetahuan menggunakan uji Wilcoxon Sign Rank dan variabel efikasi diri dan sikap menggunakan uji Paired T Test.

\section{HASIL}

Berdasarkan Tabel 1 diketahui siswa yang mengikuti penelitian lebih banyak berjenis kelamin perempuan sebesar 22 siswa $(62,9 \%)$ dibandingkan jenis kelamin laki-laki sebesar 13 siswa $(37,1)$. Dari 35 siswa terdapat 1 siswa yang pertama kali mencoba merokok pada usia 13 tahun.

Data hasil pengukuran pengetahuan sebelum dan sesudah menggunakan Uji nonparametrik yaitu Uji Wilcoxon Sign Rank. Berdasarkan uji tersebut diperoleh perbedaan pengetahuan sebelum dan sesudah intervensi pada siswa yang dapat dilihat pada tabel.

Berdasarkan Tabel 2 diketahui bahwa dari 35 siswa, rata-rata pengetahuan sebelum intervensi sebesar 16,06 dan setelah dilakukan intervensi meningkat menjadi 17,54 . Nilai $p$ value $(0,005)$ lebih kecil dibandingkan 0,05 artinya terdapat perbedaan antara pengetahuan sebelum dan sesudah intervensi video ceramah dengan alat praga Dangers of Smoking.

Data hasil pengukuran efikasi diri sebelum dan sesudah menggunakan uji parametrik yaitu Uji Paired $T$ Test. Berdasarkan uji tersebut diperoleh perbedaan efikasi diri sebelum dan sesudah intervensi pada siswa yang dapat dilihat pada tabel.

Pada tabel 2, rata-rata efikasi diri dari 35 siswa sebelum intervensi adalah sebesar 33,09 dan setelah dilakukan intervensi meningkat menjadi 34,74 . Nilai $p$ value $(0,023)$ lebih kecil dibandingkan 0,05 artinya terdapat perbedaan antara efikasi diri sebelum dan sesudah intervensi video ceramah dengan alat praga Dangers of Smoking.

Data hasil pengukuran sikap sebelum dan sesudah menggunakan uji parametrik yaitu paired t-test. Berdasarkan uji tersebut didapat perbedaan sikap sebelum dan sesudah intervensi pada siswa yang dapat dilihat pada tabel.

Sesuai dengan Tabel 2, diketahui bahwa rata-rata sikap pada 35 siswa sebelum intervensi adalah sebesar 38,71 dan setelah dilakukan intervensi meningkat menjadi 40,83. Nilai p-value sebesar 0,019 lebih kecil dari 0,05 artinya ada perbedaan bermakna antara sikap sebelum dan sesudah intervensi video ceramah dan alat peraga Dangers of Smoking.

Tabel 1. Distribusi Responden Menurut Karateristik (n=35)

\begin{tabular}{lcc}
\hline \multicolumn{1}{c}{ Karakteristik } & $\mathbf{f}$ & $(\boldsymbol{\%})$ \\
\hline Jenis Kelamin & & \\
\hline - Laki-laki & 13 & 37,1 \\
- Perempuan & 22 & 62,9 \\
\hline \multicolumn{2}{l}{ Pertama Kali Pernah Merokok } & \\
\hline - Pernah & 1 & 2,9 \\
- Tidak Pernah & 34 & 97,1 \\
\hline
\end{tabular}

Tabel 2. Perbedaan Pre-test dan Post-test Pengetahuan, Efikasi Diri dan Sikap

\begin{tabular}{lrrrr}
\hline \multicolumn{1}{c}{ Variabel } & n & Mean & Mean Diff. & P-Value \\
\hline \multicolumn{2}{l}{ Nilai Pengetahuan } & & & \\
\hline - Pre-test & 35 & 16,06 & \multirow{2}{*}{1,48} & 0,005 \\
- Post-test & 35 & 17,54 & & \\
\hline Nilai Efikasi & & & & \multirow{2}{*}{0,023} \\
\hline - Pre-test & 35 & 33,09 & \multirow{2}{*}{1,65} & \\
- Post-test & 35 & 34,74 & &
\end{tabular}

Nilai Sikap 


\begin{tabular}{cllll}
\hline - Pre-test & 35 & 38,71 & 2,12 & 0,019 \\
- Post-test & 35 & 40,83 &
\end{tabular}

\section{PEMBAHASAN}

Pendidikan kesehatan dengan memakai video ceramah mengenai bahaya merokok akan meningkatkan pengetahuan siswa. Hal ini disebabkan video ceramah menjelaskan bahan kimia rokok, dampak negatif merokok bagi kesehatan perokok aktif dan perokok pasif. Alat peraga Dangers of Smoking menggambarkan bahaya merokok pada sistem pernapasan manusia yang ditangkap oleh pencaindera pengelihatan (mata) menyalurkan kurang lebih 75 - 87\% pengetahuan dan sisanya melalui pancaindera lainnya. ${ }^{12}$ Perkembangan intelektual pada usia sekolah berkembang secara pesat. Pada fase ini remaja merupakan fase yang sangat potensial dari aspek kognitif, emosi dan fisik. ${ }^{13}$ Penelitian Alamsyah dkk tahun 2017 menyatakan bahwa pengetahuan yang tinggi terhadap bahaya merokok pada remaja akan lebih memperkecil kemungkinan remaja untuk merokok.

Teori Extended Paralell Process Model menjelaskan bahwa pesan yang disampaikan kepada sasaran pendidikan mengenai bahaya merokok akan melalui proses pemrosesan. Menurut Leventhal (1971) dalam Zonouzy dkk tahun 2019, pesan akan diproses dalam kognisi individu. Hal tersebut menyebabkan terjadinya peningkatan informasi yang telah diberikan melalui media video ceramah dan alat peraga Dangers of Smoking.

Hasil penelitian ini sejalan dengan temuan Yulinda \& Fitriyah tahun 2018, bahwa metode ceramah dan audio-visual dapat meningkatkan pengetahuan dan sikap sesudah dan sebelum penyuluhan tentang SADARI di SMKN 5 Surabaya. Peneliti lainnya yaitu Hepia Guspita (2017) menyatakan bahwa metode ceramah efektif dalam meningkatkan pengetahuan dan sikap tentang HIV/AIDS pada remaja SMK Tritech Informatika dan SMK Namira Tech Nusantara.

Efikasi diri menggambarkan kemampuan diri seseorang atas sesuatu. Seseorang yang memiliki efikasi diri tinggi akan merasa yakin mampu mengubah perilaku dirinya sendiri, sedangkan seseorang yang memiliki efikasi diri rendah akan merasa dirinya telah gagal atau tidak mampu mengubah perilakunya.

Berdasarkan hasil penelitian dengan menggunakan uji Paired T Test diperoleh nilai $p$-value sebesar 0,023 artinya ada perbedaan signifikan antara efikasi diri siswa sebelum dan sesudah dilakukan intervensi. Efikasi diri mengenai bahaya merokok disertai dengan peragaan dampak bahaya merokok menggunakan alat peraga Dangers of Smoking dapat meningkatkan penilaian diri siswa mengenai bahaya merokok.

Penelitian Haryati \& Asnawi Abdullah (2016) menyatakan bahwa terdapat hubungan efikasi diri dengan perilaku merokok remaja. Efikasi diri dapat mendorong remaja untuk berperilaku merokok. Jika seorang remaja memiliki efikasi diri yang tinggi maka remaja tersebut tidak merokok. Apabila remaja tersebut memiliki efikasi diri yang rendah maka siswa berperilaku merokok.

Pemberian pendidikan kesehatan tentang dampak bahaya merokok akan menambah efikasi diri. Teori Extended Paralell Process Model menjelaskan bahwa pesan yang disampaikan kepada sasaran pendidikan mengenai bahaya merokok akan melalui sebuah proses pemrosesan. Proses pemrosesan akan terjadi dalam kognisi individu. Bagian ini berkaitan dengan penerimaan efikasi diri. Hasil dari efikasi diri sangat penting dalam perubahan perilaku. $^{13}$

Alat peraga tentang bahaya merokok menggambarkan proses merokok yang dapat merusak organ dalam tubuh sehingga menimbulkan efikasi diri untuk tidak merokok. Pesan persuasi dengan efikasi tinggi dan ancaman tinggi akan menghasilkan tingkat ketakutan yang tinggi dan menyakinkan subjek penelitian bahwa ancaman bahaya merokok dapat dihindari. ${ }^{8}$ Peningkatan efikasi bertujuan untuk membuat seseorang mampu melakukan pengelolaan diri dan mengarahkan dirinya sendiri pada perilaku-perilaku yang diinginkan dan seharusnya dilakukan yaitu tidak merokok. ${ }^{15}$

Penelitian ini sesuai dengan penelitian Jannah (2019) yang menyatakan bahwa metode kombinasi permainan proaktif dan demonstrasi bisa meningkatkan pengetahuan 
dan efikasi diri terhadap kekerasan seksual remaja. Hal tersebut menunjukkan bahwa demontrasi dengan menggunakan alat peraga mampu meningkatkan pengetahuan dan efikasi diri. Penelitian lainnya yaitu Kurnianingtyas (2017) menyatakan bahwa terdapat pengaruh intervensi pendidikan kesehatan tentang manajemen laktasi terhadap efikasi diri ibu primigravida trisemester III.

Sikap ialah respon tertutup seseorang terhadap suatu stimulus atau objek tertentu yang telah melibatkan faktor pendapat dan emosi yang bersangkutan. Berdasarkan hasil penelitian dengan menggunakan uji Paired $T$ Test diperoleh nilai p-value sebesar 0,019. Artinya terdapat perbedaan signifikan antara sikap siswa sebelum dan sesudah intervensi. Pengetahuan mengenai bahaya merokok disertai dengan peragaan dampak bahaya merokok menggunakan alat peraga Dangers of Smoking dapat meningkatkan kesadaran dan respon siswa mengenai bahaya merokok.

Sikap berhubungan negatif dengan perilaku merokok. Jika seseorang remaja memiliki sikap baik terhadap bahaya merokok, maka remaja tersebut akan mengurangi risiko perilaku merokok. ${ }^{17}$ Pada penelitian ini siswa terjadi peningkatan sikap sebelum dan sesudah intervensi bahaya merokok. Hal ini dapat dilihat sikap pada aspek kognitif yaitu percaya atau menyakini bahwa rokok mengandung bahan berbahaya dan berdampak buruk bagi kesehatan bagi perokok aktif dan pasif serta sikap pada aspek afektif yaitu menyangkut perasaaan emosinal seseorang terhadap rokok.

Menurut Aryani (2010) dalam Alamsyah dkk tahun 2017, sikap berkaitan erat dengan perilaku merokok. Sikap akan menentukan seseorang berperilaku terhadap sesuatu objek baik yang disadari atau tidak disadari dan sikap dipengaruhi oleh pengetahuan, keyakinan dan emosi seseorang. Peningkatan sikap bahaya merokok melalui media video ceramah dengan alat peraga Dangers of Smoking dapat meningkatkan pengetahuan dan efikasi diri seseorang. Teori Extended Paralell Process Model dijelaskan bahwa efikasi diri dapat menimbulkan kontrol bahaya terhadap bahaya merokok. Pada kontrol bahaya ini terdapat proses kognitif atau pengetahuan dan mengarah pada perubahan sikap remaja. ${ }^{9}$
Penelitian ini sejalan dengan Rusmilawaty (2016) yang menyatakan bahwa ada perubahan sikap sebelum dengan sesudah penyuluhan metode ceramah bahaya merokok pada perokok aktif di Desa Tritajaya. Penelitian ini sejalan dengan penelitian yang dilakukan Adam \& Engkeng (2019) terdapat perbedaan sikap bahaya merokok pada kelompok kontrol dan kelompok eksperimen setelah diberikan intervensi penyuluhan bahaya merokok pada siswa laki-laki di SMK Cokroaminoto Kota Manado

\section{KESIMPULAN}

Terdapat pengaruh metode video ceramah terhadap peningkatan pengetahuan, efikasi diri dan sikap bahaya merokok pada siswa kelas VII SMP Negeri 32 Kota Samarinda

\section{SARAN}

Diharapkan pihak sekolah memberikan pendidikan kesehatan berkelanjutan mengenai bahaya merokok melalui metode video ceramah dengan alat peraga Dangers of Smoking agar siswa terhindar dari perilaku merokok.

Bagi masyarakat, diharapkan orang tua selalu mengontrol kegiatan siswa ketika di sekolah maupun di luar sekolah. Selain itu juga agar selalu memberikan nasihat mengenai dampak merokok bagi kesehatan agar siswa memiliki resiko rendah perilaku merokok.

Bagi peneliti selanjutnya, diharapkan peneliti selanjutnya mampu merencanakan dan merancang media kesehatan tentang bahaya merokok dalam metode atau media lainnya yang menarik bagi sasaran pendidikan.

\section{UCAPAN TERIMA KASIH}

Ucapan terima kasih disampaikan kepada Fakultas Kesehatan Masyarakat Universitas Mulawarman dan SMP Negeri 32 Kota Samarinda yang telah berkontribusi dalam penelitian ini, sehingga penelitian ini dapat terlaksana dengan baik.

\section{DAFTAR REFERENSI}

1. Drope J, Schluger NW. The Tobacco Atlas Sixth Edition. 6th ed. Daniel JM, J.Hsu J, editors. Atlanta, Georgia 30303 USA: the America Cancer Socienty, Inc; 2018. 
2. Sutha DW. Pengetahuan dan Perilaku Merokok Pelajar Sekolah Menengah Pertama. J Manaj Kesehat Yayasan RS Dr, Soetomo. 2018;4(1):47-60.

3. Wijayanti E, Dewi C, Rifqatussa'adah. Faktor-faktor yang Berhubungan dengan Perilaku Merokok pada Remaja Kampung Bojong Rawalele, Jatimakmur, Bekasi. Glob Med Heal Commun. 2017;5(March):194-8.

4. Haryati W, Asnawi Abdullah B. Self Efficacy dan Perilaku Merokok Remaja. J Ilmu Keperawatan. 2016;3(2).

5. Nugroho RS. Perilaku Merokok Remaja. J Unair. 2017;

6. Alamsyah A, Nopianto. Determinan perilaku merokok pada remaja. J Endur. 2017;2(1):2530.

7. Jannah M, Murni NNA. Penggunaan Media Audio Visual Meningkatkan Kepatuhan Konsumsi Tablet Tambah Darah Pada Ibu Hamil. J Kesehat Prima. 2019;13(2):108-14.

8. Eriyanto, Zarkasih IR. Model Persuasi yang Efektif Dengan Menggunakan Pendekatan Rasa Takut ( Fear Appeal ) : Studi Eksperimen Bahaya Rokok di Kalangan Remaja. J Komun Indones. 2018; VII(1):87-98.

9. Zonouzy VT, Niknami S, Ghofranipour F, Montazeri A. An educational intervention based on the extended parallel process model to improve attitude, behavioral intention, and early breast cancer diagnosis: A randomized trial. Int J Womens Health. 2019;11:1-10.

10. Kementrian Kesehatan RI. Infodantin : Situasi Umum Konsumsi Tembakau di Indonesia. Jakarta Selatan: Kementrian Kesehatan RI; 2018.

11. Dinas Kesehatan Kota Samarinda. Rekapitulasi Laporan PKPR Usia 10-19 Tahun Periode Januari-Desember 2018. Samarinda; 2018.

12. Sari SA, Sulaeman S, Idriani. Pengaruh Paket Edukasi Tanda Bahaya Kehamilan Melalui
Media Booklet, Audiovisual Dan Kombinasi Terhadap Pengetahuan Dan Sikap Ibu Hamil the Effect of Education Packages of Pregnancy Hazards Through Booklet, Audiovisual and Combination Media on Knowledge. J Kesehat. 2018;3(2):356-72.

13. Ali M, Asrori M. Psikologi Remaja. Edisi 1. Jakarta: Ikrar Mandiriabadi; 2010.

14. Yulinda A, Fitriyah N. Efektivitas Penyuluhan Metode Ceramah Dan Audiovisual Dalam Meningkatkan Pengetahuan Dan Sikap Tentang SADARI Di SMKN 5 Surabaya. J Promkes. 2018;6(2):116-28.

15. Waskam A, Sugiharto, Supriyo. Pengembangan Model Konseling Kelompok dengan Teknik Pengelolaan Diri untuk Meningkatkan Efikasi Diri Siswa Terhadap Perilaku Berisiko Merokok di SMK YPT 1 Purbalingga. J Bimbing Konseling. 2016;5(2):8.

16. Kurnianingtyas RT. Pengaruh Pendidikan Kesehatan tentang Manajemen Laktasi terhadap Efikasi Diri Menyusui pada Ibu Primigravida Trimester III. Universitas Diponegoro; 2017.

17. Wijayanti E, Dewi C, Rifqatussa'adah. Faktor-faktor yang Berhubungan dengan Perilaku Merokokpada Remaja Kampung Bojong Rawalele, Jatimakmur, Bekasi. Glob Med Heal Commun. 2017;5(3).

18. Rusmilawaty. Pengaruh Penyuluhan Metode Ceramah tentang Bahaya Rokok terhadap Perubahan Sikap. J Vokasi Kesehat. 2016;II(2):113-8.

19. Adam REP, Engkeng S. Pegaruh Penyuluhan Kesehatan tentang Bahaya Merokok Terhadap Sikap Peserta Didik Laki-laki di SMK Cokroaminoto Kota Medan. J kesmas. 2019;8(7). 